\title{
Beneath a Steel Sky: A Musical Characterisation of Class Structure
}

\section{Andra Ivănescu ${ }^{1}$}

Received: 28 September 2018 / Accepted: 3 October 2018 / Published online: 25 October 2018

(c) The Author(s) 2018

\begin{abstract}
This article proposes Revolution Software's Beneath a Steel Sky (1994) as a starting point for the analysis of the relationship between music and social class in video games. While other issues of representation have been studied extensively within game studies (gender representation in particular), the representation of class remains an underexplored area. Furthermore, the relationship between video game music and socio-cultural aspects of video game studies is also rarely examined beyond issues of race, ethnicity, and cultural appropriation. This article draws connections between these two underexplored areas and analyses the musical characterisation of class in the 1994 cyberpunk adventure game, which takes places largely in a literally stratified metropolis where the three levels of the city act as representations of the three social classes. Here, music plays an important role in terms of environmental storytelling, both as semiotic shorthand, and as a reflection of the affordances available to the inhabitants of the city.
\end{abstract}

Keywords Class $\cdot$ Video games $\cdot$ Video game music $\cdot$ Ludomusicology

\section{Introduction}

Issues of representation in video games have been important to video game studies for over two decades, largely focussing on gender (Cassell and Jenkins 1998; Dietz 1998; Kafai et al. 2016; Lynch et al. 2016), and, to a lesser degree, LGBTQ issues (Consalvo 2003; Ruberg and Shaw 2017), and race (Burgess et al. 2011; Leonard 2006; Monson 2012). The representation of class, however, remains underexplored, even amongst critiques of video games as agents of capitalism.

All editorial decisions for this article, including selection of reviewers and the final decision, were made by guest editor Dr. Kenny McAlpline.

Andra Ivănescu

Andra.Ivanescu@brunel.ac.uk

1 Brunel University, London, UK 
Virtual economies and virtual worlds have been seen to reproduce both real world economic systems and real-world ideologies (Castronova 2005; Rettberg 2008) and subsequently reproducing social strata and power relations. While most of these critiques have focused specifically on how these relations are reproduced in MMORPGs, where practices like gold farming quite explicitly mirrored real-life power relations, some have also focused on single-player games, particularly their neoliberal affinities. An example of this is the analysis of Grant Theft Auto: Vice City (2002) offered by Dyer-Whiteford and de Peuter, in which they note that "Vice City's lead, Tommy Vercetti, is neoliberal theory incarnate: if the most famous line of the eighties film Wall Street is Gordon Gekko's 'greed is good,' then the equivalent for Vice City's eighties parody is Tommy Vercetti's statement 'I work for money." (DyerWhiteford and de Peuter 2009) Vice City, however, with its satirical tone, acts as both an agent of the hegemony, and its subverter. These elements of subversion can, of course, be found throughout video games, both as emergent gameplay, where players take it upon themselves to critique society by taking advantage of game affordances, but also as embedded narrative and procedural elements.

Discussions of social classes and power relations are often implied within these broader conversations, but rarely find themselves at the centre of them. Moreover, the relationship between video game music and socio-cultural aspects of video game studies is also rarely examined beyond issues of race, ethnicity, and cultural appropriation, with some notable exceptions. ${ }^{1}$ This article aims to begin filling these gaps and drawing some clear connections between class, music, and video games, by looking at Revolution Software's 1994 Beneath a Steel Sky (1994).

\section{Beneath a Steel Sky}

Beneath a Steel Sky is a cyberpunk point-and-click adventure game developed by the UK Company Revolution Software in 1994. Directed by Charles Cecil, the game also famously features the art of Dave Gibbons, comic book artist of Watchmen (1986-1987), and the design, dialogue, and music of Dave Cummins. The game was widely critically acclaimed, both at the time, and since its remaster: it originally received a Golden Joystick Award for 'Best Adventure' (Cecil 2016), and is currently found on countless 'Best Adventure Games' lists, like Richard Cobbett's "29 Essential, Must-Play Adventure Games", under the "Essential Games: The Classics" category. (Cobbett 2017)

The game was developed by Revolution after their breakthrough Lure of the Temptress (1992) and before the start of their long-standing series Broken Sword (1996-2014). The team, particularly Cecil and Gibbons, have discussed the game extensively since its twentieth anniversary, often emphasising the historical context of the game's production, and how the game itself was influenced by real-life social tensions. As Cecil phrased it: "You had the rise of the yuppies, the mega-rich, and

\footnotetext{
${ }^{1}$ For instance, Kiri Miller's ethnomusicological exploration of the music in Grand Theft Auto: San Andreas does focus on the issue of race quite significantly. (Miller 2007).
} 
the ultra-poor. There was a lot of conflict, and that influenced our setting." (Cecil, quoted in Kelly 2016) Gibbons has expressed similar sentiments about the game, noting:

"We were designing a dystopian future, so we looked at how society was in the present day and imagined how it could move forward. Beneath a Steel Sky was made at the height of Thatcherism. A consumer society with divisions that were deeper than ever. And these ideas were floating around in our heads when we created the game." (Gibbons, quoted in Kelly 2016)

There are at least two significant points that Gibbons stresses here. Firstly, it is particularly notable that he acknowledges the impact of Margaret Thatcher's policies and public persona on their work. While the time at which the game was developed was hardly "the height of Thatcherism", as Gibbons notes, since she had served as Prime Minister of the United Kingdom between 1979 and 1990 and was no longer in power by the time of the game's development, this influence is undeniable, as Cecil also echoes on a number of occasions, including during a talk at the Yorkshire Games Festival, where he echoes her infamous denial of the existence of society. (Cecil 2016)

The second notable aspect of Gibbons's statement is the implication that, while they were clearly influenced by these ideas, they did not set out to create a deliberate allegory with their dystopian game. Cecil himself is candid about this, noting during the same Yorkshire Games Festival talk, that he: "didn't realise until somebody did a wonderful interview a couple of years ago — and it became quite clear-it had never struck me, it had never been deliberate, that actually the story was all about what was going on at the time." (Cecil 2016) In other words, Beneath a Steel Sky is not a deliberate commentary on the state of society in the same way that many dystopian works are, but the embodiment of what Fredric Jameson describes as the "political unconscious." (Jameson 1983)

Jameson argues for what he calls "the priority of the political interpretation of literary texts." (p. 1) His central thesis here is that "there is nothing that is not social and historical-indeed, that everything is 'in the last analysis' political," further describing cultural artefacts as "socially symbolic acts." (p. 5) This article argues that Beneath a Steel Sky is, like the literary works that Jameson analyses, such a symbolic act, its "Utopian impulses" (p. 286) evident in its dystopian metropolis.

\section{There is No Such Thing as Society in Union City}

Lyman Tower Sargent defines dystopia as "a nonexistent society described in considerable detail and normally located in a time and space that the author intended a contemporaneous reader to view as considerably worse than the society in which the reader lived" (1994, p. 154).

Beneath a Steel Sky is set in a dystopian future with two distinct environments which reflect two distinct (but certainly not discrete) scientific traditions, both describing worlds worse than our own: "the Gap" draws on post-apocalyptic films 
like Mad Max 2 (1981), presenting a desert world of scavenging tribes, ${ }^{2}$ while Union City, the metropolis in which all of the gameplay takes place, draws on the cyberpunk worlds of William Gibson and others. While the game is theoretically set in Australia, it is profoundly British in terms of its humour, its accents, its use of language, and its themes. Language is perhaps the most obvious clue: as one reviewer notes, "for a game supposedly set in Australia, most of the people you meet have stereotypical regional English accents. I can't think of a game with more northerners in it." (Kelly 2016) Indeed, while the main character has a strong American accent, the majority of the NPCs (non-player characters) sport a range of northern English accents. Moreover, there are often discrepancies between the British terms used in the spoken dialogue, and the written captions which often use the corresponding American or Australian term ("lift" and "elevator" for instance).

The British point of view is also noticeable in the story surrounding the protagonist's name: Robert Foster. Robert is an orphan, found in the desert by a tribe after a helicopter crash. He is given the name 'Foster' after his adoptive father encounters a label for Foster's lager, and finds the double meaning poignant, as Robert becomes his foster child. ${ }^{3}$ This perpetuates the perception of the Foster's brand of lager as an Australian staple, perception developed through extensive marketing campaigns in the United Kingdom (and the United States) from the 1980s onwards, although, as Leanne White notes, "Foster's Lager is generally regarded as being famous for its unpopularity with Australian men and women." (White 2009, citing Rochfort 2008) In other words, the use of Foster's as a narrative device is more indicative of a British point of view than an Australian setting, as it is based on a common misperception surrounding a brand that is, in fact, not popular in its native country. These are only small indications of the profound Britishness of the game, which becomes most evident in its themes, particularly its preoccupation with class.

The primary setting of the game is Union City, the metropolis that Foster is from, and whence he unwittingly returns. The plot follows Foster's journey as he is abducted from the Gap by a heavily armed group that intends to bring him back to the city for unknown reasons. The helicopter carrying the group crashes into Union City, leaving Foster alone, trying to make his way get back to his tribe. He journeys through the three levels of the city which form a reverse High-Rise structure (Ballard 1975), in which the working class occupies the highest level of the metropolis, the middle class the middle level, and the upper classes occupy the opulent lower level. Throughout his journey, he uncovers both the deep injustices of the city and a deeper conspiracy at play, before deposing the tyrannical ruler of the metropolis and returning from whence he came.

Farca and Ladeveze (2016) argue that "video game dystopias [critical dystopias] often place the prospect of hope into the player's hands," where "the player assumes the role of the dissident and becomes directly responsible for laying the foundations of the better society" (Farca and Ladeveze 2016, p. 4). In this sense, the dystopia of

\footnotetext{
${ }^{2}$ Gibbons acknowledges Mad Max 2 as a distinct influence on the visual design of the characters in the gap. (Kelly 2016).

3 The brand name is omitted in some versions of the game due to copyright reasons.
} 
Beneath a Steel Sky follows the pattern of numerous video game dystopias, in which the authoritarian metropolis often plays an important part. From the exploited children in Assassin's Creed: Syndicate (2015) elvish ghettoes in Dragon Age 2 (2011) and the Midgar slums in Final Fantasy VII (1997), visions of poverty act as confirmation of the need for a player-hero to intervene, and the class system is often heavy-handedly portrayed and only superficially explored.

In Beneath a Steel Sky, the representation of class is unusually complex, however, and Robert's journey through the city can be interpreted as a metaphorical rising through the class system, as he begins his downward journey in the workingclass area and travels to the upper-class area. Throughout Foster's journey, players become familiar with the class system in Union City through interactions with both NPCs and environmental storytelling. Henry Jenkins argued that "choices about the design and organization of game spaces have narratological consequences," (Jenkins 2004, p. 129) focussing on environmental storytelling as particularly important in the case of videogames. This is certainly true in Beneath a Steel Sky, where embedded narrative is particularly significant as a form of communicating information to the player. Specifically, the class system is characterised aesthetically, and power relations, occupations, capital, and affordances are also implied through the design of the space.

Affordances are particularly interesting here, as they convey a particular understanding of social class. The concept of "affordances" is one borrowed from psychological ecology, and is described by Linderoth, drawing on Gibson, as follows:

"The main idea of affordance, as originally developed, is to address the reciprocal relation between humans and the environment [...] The environment offers the individual different ways of acting. These offers are called affordances, and an important part of the original formulation of the concept is that affordances are relative to an organism (relative between species as well as between individuals)." (Linderoth 2013, drawing on Gibson 1986)

In this article, the concept of affordances is used to describe how class relations are constructed in Union City through environmental storytelling. What the different levels of the metropolis afford the NPCs - and, to some degree, the player-dictate what they are able to do, and how they are able to affect the world around them. The spaces that are available, their structure, their aesthetic qualities, and their types, are relatively limited in what they afford the virtual inhabitants of these areas. The player, however, can manipulate these to a higher degree than the NPCs, demonstrating that these are still relative to the character inhabiting the space. In this context, the concept of affordances is a useful tool in analysing these environments and how they characterise the class system at play.

\section{Embedded Narrative in Beneath a Steel Sky}

The three levels of Union City act as distinct environments in which class plays a significant role, and the three soundscapes through which the player travels characterise class in unique ways. 
The player begins the game in the upper level largely inhabited by working-class NPCs. The limited affordances of the population on this level become clear as the player travels through the space: all the locations are work-related (mostly factories) and there are no spaces for leisure or individual time. It is also revealed to the player that inhabitants of this level often cannot travel to the other levels, and their access can be completely restricted if they are made a D-LINC, which blocks their ID cards from using the central lift. Aesthetics are also significant here. In terms of the visual design, the colour palette is quite limited: the reddish-brown overviews of the city give way to greys, which dominate the factory environments. There are also no decorative elements to the rooms, which are presented as strictly utilitarian. The music here is particularly repetitive, with the "proletariat music" of this area also having a distinctive Soviet flavour, its March rhythm and minor key blending with the industrial sound effects of the factories. The exterior loop, which plays as the player walks through the level (but not in specific locations) is also notably the shortest of the three outdoor themes, emphasising the repetitiveness of the music and its inescapability.

When the player accesses the middle level of Union City, it is immediately evident that there is a profound class difference here. The aesthetic changes are striking: the environment is brighter and greener, with numerous (artificial) plants decorating it, the grey of machinery replaced with beige walls and walkways, reminiscent of the USS Enterprise in Star Trek: The Next Generation (1987-1994) in their soothing blandness. There are a number of work spaces here as well, but these are smaller businesses, largely run by their owners. The occupations themselves speak to a certain perception of the middle class, as the three businesses present are a plastic surgeon, a travel agent, and an insurance broker, all services that are likely provided to the higher class citizens rather than the blue collar workers above. Furthermore, there are spaces here which speak to the broader affordances available to the middleclass NPCs: there are private apartments, in which the individuality of the inhabitants is emphasised through décor and personal possessions, as well as areas with benches, presenting small opportunities to rest and reflect. Critiques of the social ambitions of the middle class are also present in these spaces: for instance, Lamb, who manages a factory on the working-class level, is revealed to own a bookcase that does not contain any books, only book covers to give the impression that he is 'cultured'.

The sound and music of the middle level emphasise all of these characteristics. Firstly, the environmental music in the outside area of the level-the track titled "Belle Vue"- is significantly longer than the pathway music in the upper level. Stylistically, it is much more Muzak than it is March, its rhythm and melody relaxed and playful. Furthermore, the bridge of this particular track introduces a version of the main theme from the upper level, the soundspace already suggesting the increased mobility available to the population of this level: they have access to the lower-class space and its music, but the working-class population does not have access to these areas. There is also an important aural commodity introduced here: silence. The player first encounters an environment with no music when entering the flat of the police officer who is murdered earlier in the game. The silence is only punctuated by the bubbling sound of the aquarium in the room (both flats also interestingly feature 
pets) and plays a dual function here, signifying both the availability of personal aural space, free from the sounds of workspaces (factories in particular), but also the absence of human life, as the inhabitant of the flat has been killed.

The lowest level of the game features more diverse spaces, and certainly more decorated ones. The player is first introduced to the much more luxurious outdoor area, its pond and greenery already suggesting the greater affordances of its population. The other areas speak to the range of opportunities available to the upper-class inhabitants, with spaces ranging from those designed specifically for leisure (like the bar) to those occupied by formal institutions (like the courthouse). The diversity of décor is most evident when comparing the spaces on the opulent side, like Mrs. Piermont's flat, which has a private elevator and features a Greek statue in its brightly coloured living room, to the utilitarian morgue, monochrome and bare. Some of the scenes of the game which take place here emphasise the absurdity of the ruling classes and the arbitrary nature of the systems in place. For instance, during a courtroom episode, a judge expresses a disregard for justice, and nearly sentences an NPC to death because of a very minor offence (an officer got "very wet") that they had not even committed.

The main aural characteristic of this level is also the diversity of its soundscapes. The environmental music in the outdoor area incorporates both previous themes, suggesting that the population on this level has access to all the areas in the city. The main theme of this level has clear Baroque influences and suggests a harpsichord sound, drawing on the long-standing association of classical music with the upper classes. While each space has a somewhat distinct sound, the most interesting area is Club St. James, the bar, which features a jukebox, as well as a resident band. The player can interact with the jukebox after an initial conversation with the machine, during which the player-character (Foster) laments: "Oh lord! It's mostly COUNTRY and WESTERN!" and decides that only the three songs by the resident band are viable options to play. This is the first time that music is ostensibly diegetic in the game, and it is also the first time that the player-character has a choice in terms of what they hear. The issue of genre is not insignificant here, and what the extensive collection of country and western that cannot be heard implies about the tastes of the elites of Union City is certainly an interesting point, but plays a minimal role in the game, as it is limited to a comment meant to be humorous rather than poignant. The three songs that the player can listen to- "You Search, But You Find Nothing" (a meta-joke common to the adventure genre), "As Cool As You" and "Longbeach" - can be described as inoffensive smooth jazz numbers, which are also quite brief (the shortest is $36 \mathrm{~s}$, and the longest $2 \mathrm{~min}$ and $6 \mathrm{~s}$ ). Genre, however, is not quite as significant as the ability to choose what music is played, in and of itself mirroring the greater affordances of the upper classes. Not only do the people of this level have access to music, but they have greater choices in what they can listen to, and even have access to a live band, which the player can briefly observe in concert.

Alongside the opulent areas of the upper level, there are a number of darker areas here, including a church and a morgue, hiding deactivated androids and a number of corpses (stored in lockers), respectively. Here, silence, punctuated in the church only by the sounds of wind blowing, signifies the absence of life and contributes to the disconcerting nature of the spaces. 
The game features two other important areas, which are not truly part of the metropolis and therefore do not directly comment on the class system. Both spaces are related to LINC (Logical Inter-Neural Connection), the artificial intelligence which controls the entire city: one is the virtual world of LINC, and the other is the underground area in which LINC's mainframe resides. The sound in these spaces is also an important part of the environmental storytelling, the more overtly cyberpunk virtual space featuring a distinctly electronic sound, and the underground area juxtaposing a menacing heartbeat-like sound over the music, suggesting LINC's simultaneously organic and inorganic nature.

\section{The (Musical) Characterisation of Class}

The class system of Union City is never the focus of Beneath a Steel Sky and is not overtly discussed in game, but its environmental storytelling demonstrates an undeniable preoccupation with class. Born out of a specific political context, as well as a broader cultural interest in social class, which Crompton and Scott describe as an "endless source of fascination for the British," (Crompton and Scott 2000, p. 1) the representation of class in the game has clear Marxist underpinnings in terms of the relationship between classes, which are both oppressive and antagonistic. This is best exemplified through the relationship between Lamb, the only middle-class supervisor the player encounters on the working-class level who treats his employees unfairly, and Anita, his employee. Anita is notably the only non-white character on any level, and one of the few characters who die as part of the plot of the game. As a dissident, actively starting a class war, she provides invaluable help to the player using her hacker skills, although she had already been stripped of all her rights, her assets had been frozen, and her mobility had already been restricted before the player encounters her. Her work against the system is also what leads to her untimely death.

The affordances of the environment describe an almost Weberian class situation, described as:

"The typical chance for a supply of goods, external living conditions, and personal life experience, in so far as this chance is determined by the amount and kind of power, or lack of such, to dispose of goods or skills for the sake of income in a given economic order." (Weber 1961, via Edgell 2008)

While the economic power of the citizens is not explicitly described, the spaces themselves suggest what living conditions and personal life experiences are available to the population of each level. The upper level only contains work spaces, the life conditions and personal life experiences of its inhabitants literally limited to labour. Through Lamb, the player learns that while the middle level inhabitants can travel to the upper level, the reverse is restricted, and can be blocked altogether, emphasising the power relations between the two levels. In the middle-level, the affordances implied by the environment include both more possibilities in terms of life experience (travel, for instance), and personal space, which does not seem to exist on the upper level. The lower level clearly offers the highest amount of possibilities to 
its inhabitants, including higher-level employment in public institutions, as well as leisure and personal spaces. Aesthetics are also significant here. Visually, beyond the diversification of colour pallets, there is an increase in decoration as the player traverses the levels, from the purely functional factories of the upper level, to the elegant park of the lowest level. Visual and thematic elements, however, are emphasised consistently through the sound and music of the game, which provide their own characterisation of class.

Throughout these areas, sound and music play an important part in terms of environmental storytelling, revealing the aural affordances available to the inhabitants of Union City. In the upper level, music also suggests the limited opportunities available to the blue-collar workers who live here. The "Walkway" theme features a repeating rhythmic formula and a simple bass line which continuously ascends and descends in a musical characterisation of daily drudgery. Its repetition is more evident, as the theme itself is shorter than the two other outdoor themes, becoming jarring to the player themselves as they return to the walkway again and again. The music in the interiors blends seamlessly with the industrial sounds of machines churning, emphasising the dominance of work in this area. In the second level there is already more music, the inclusion of the upper level theme also suggesting the mobility available to middle-class citizens. The inclusion of personal space without music suggests that silence, as individual sonic space, is a commodity unavailable to the working-class, who cannot escape the constant noise pollution, the sound of their work dominating every nook and cranny. Finally, the lower level offers a wider variety of music, in the same way in which it offers a wider variety of space. While the outdoor "Park" theme is significantly longer and musically more complex than the "Walkway" theme, this level also introduces diegetic music, in addition to the quiet spaces of the institutions. The diegetic music in the form of the jukebox suggests the level of control that the citizens of this level have over their lives: they have more choices in terms of space, leisure, and opportunities for employment, and this is mirrored in the choices they have over music and sonic space.

The class system in the ironically titled Union City is not only described relationally, but also in terms of economic, cultural, and social capital. (Bourdieu 1986) The environments of the game make economic capital visible through the types of businesses present in each of the areas. In the first level, only factories and security offices are to be seen, and it is implied that the majority of the population (with the exception of the socially-mobile Lamb) is an employee rather than an employer. In the middle level, the economic possibilities of the population are diversified, as we encounter small business owners, as well as a wider range of businesses, including insurance and travelling companies, and a plastic surgery office. The player does not encounter employees here, as even the receptionist role in the surgery office has been taken over by a hologram, and everyone else seems to be a part of the petit bourgeoisie, either supervising citizens in the working-class level or owning/running their own businesses. The personal life experiences available to the citizens of the lower level are even more diversified, not only in terms of occupations, which here range from blue-collar work (the bouncer at the bar, for instance) to highly valued white-collar occupations (the judge, for example), with some particularly affluent citizens who do not seems to need to work at all, like Mrs. Piermont. Social capital 
is perhaps the most evident to the player, as the player-character needs to acquire and employ it, by asking Mrs. Piermont to afford him access to the member's only St. James club. Cultural capital appears to be absent on the working-class level, and its absence on the middle level is emphasised through Lamb's fake bookcase. In the upper class level, cultural capital is present in the form of access to art, again most clearly evidenced in Mrs. Piermont's flat, but also through access to music. There is, however, a deeper connection between music and cultural capital suggested through the styles referenced throughout the game.

The relationship between music, in particular musical genres and styles, and class is explored widely throughout musicology, cultural theory, and sociology. From Adorno's 'critiques' of popular music and jazz (1990) to Hebdige's analysis of subcultures (1979), and to the way in which these relationships are explored in film (Kassabian 2001). In Beneath a Steel Sky, musical styles act as semiotic shorthand, characterising class through para-musical connotations, despite the technological limitations which in turn restrict the stylistic choices available to the composer here. The music speaks volumes about these levels and the citizens who inhabit them, and the three exterior themes illustrate this best. From the Soviet flavour of the "Walkway" theme, acting as semiotic shorthand for the struggle of the proletariat (and also suggesting their impending uprising), to the playful syncopation of the "Belle Vue" theme, and finally the Baroque-inspired ornamentation and timbre of the "Park" theme. Music thus characterises class both through soundscapes that illustrate the affordances available to the citizens of Union City, and through the appropriation of musical styles, illustrating how video game music can both draw on existing musical connotations, and develop medium-specific rhetorical strategies. As Schulzke notes, "virtual dystopias [...] challenge existing institutions and ideologies in much different ways from traditional dystopian media," (2014, p. 316) and music is certainly part of the challenge.

\section{Beyond Beneath a Steel Sky}

Beneath a Steel Sky presents a uniquely clear example of Jameson's political unconscious, as it is heavily influenced by the socio-political context of its production and makes some of the divisions that had been exacerbated in early 1990s British society literal, with the player the ultimate socially mobile citizens who rejects these divisions. Music plays an important role as part of the environmental storytelling of the game, exemplifying the literalisation of both stratification and mobility, the aesthetic properties of the spaces, and the affordances implied by the space.

This dystopian vision is ideologically inflected and has a healthy dose of the absurd in its humour, both characteristics reminiscent of other profoundly British dystopias, from Nineteen Eighty-Four (Orwell 1949) to Brazil (1985), and, of course, G.J. Ballard's High-Rise (1975). While these characteristics make it part of a clear narrative tradition, they also make it stand out amongst similarly dystopian games in terms of its portrayal of class, as both more direct, and more culturally specific. Nevertheless, Beneath a Steel Sky is not entirely unique in its representation of social and political systems, as subversive tendencies can be found throughout 
video games. As Dyer-Whiteford and de Peuter note, "video games are a paradigmatic media of Empire-planetary, militarized hypercapitalism-and of some of the forces presently challenging it." (Dyer-Whiteford and de Peuter 2009, p. v) In their astute comment on the complexity of the relationship between video games and Empire, Dyer-Whiteford and de Peuter echo Jameson's final thoughts in his The Political Unconscious, where he emphasises the importance of "the simultaneous recognition of the ideological and Utopian functions of the artistic text". (Jameson, p. 290) The hegemonic and the subversive, the ideological and the Utopian, Empire and its challengers, are all offered to players, their own affordances allowing them to explore gameworlds as sociologists, anthropologists, and even musicologists, as representation is also an aural matter. As was evidenced with regards to Beneath a Steel $S k y$, sound and music can play an important part in terms of environmental storytelling, but aural representation goes far beyond it. Within the soundscapes of videogames, the relationship between music and class (and other socio-cultural aspects) relates to issues of characterisation and identification, historical and geographical perspectives, and of course intersectionality. Sound and music in games draw on existing para-musical connections, whether it is in terms of musical styles or genres, or appropriating pre-existing music as recorded artefact, but they also employ medium-specific rhetorical strategies which often remain underexplored. The relationships and strategies examined in this article are by no means exhaustive or even typical, but they reveal how the examination of social class and the aural dimension of representation constitute important interrelated puzzle pieces that are important to our understanding of the complexities of videogames as cultural texts.

Open Access This article is distributed under the terms of the Creative Commons Attribution 4.0 International License (http://creativecommons.org/licenses/by/4.0/), which permits unrestricted use, distribution, and reproduction in any medium, provided you give appropriate credit to the original author(s) and the source, provide a link to the Creative Commons license, and indicate if changes were made.

\section{References}

Adorno, T. (1990). On popular music. In S. Frith \& A. Goodwin (Eds.), On record: Rock, pop, and the written word (pp. 301-314). London: Routledge.

Ballard, J. G. (1975). High-rise. London: Jonathan Cape.

Bourdieu, P. (1986). The forms of capital. In J. Richardson (Ed.), Handbook of theory and research for the sociology of education (pp. 241-258). Westport, CT: Greenwood.

Burgess, M., et al. (2011). Playing with Prejudice: The prevalence and consequences of racial stereotypes in video games. Media Psychology, 14, 289-311.

Cassell, J., \& Jenkins, H. (1998). From Barbie to Mortal Kombat: Gender and video games. Cambridge, MA: The MIT Press.

Castronova, E. (2005). Synthetic worlds: The business and culture of online games. Chicago: University of Chicago Press.

Cecil, C. (2016). Charles cecil of revolution software on adventure games | Yorkshire games festival, YouTube. Available at: https://www.youtube.com/watch?v=SEk5aiTK-xQ\&t=816s.

Cobbett, R. (2017). 29 Essential, must-play adventure games (online article). www.uk.ign.com. Available at: https://uk.ign.com/articles/2017/05/19/29-essential-must-play-adventure-games. Accessed: 08 September 2018. 
Consalvo, M. (2003). Hot dates and fairy-tale romances: Studying sexuality in video games. In M. Wolf \& B. Perron (Eds.), The video game theory reader (pp. 171-194). London: Routledge.

Crompton, R., \& Scott, J. (2000). Introduction: The state of class analysis. In R. Crompton, F. Devine, M. Savage, \& J. Scott (Eds.), Renewing class analysis. Oxford: Blackwell.

Dietz, T. L. (1998). An examination of violence and gender role Por-trayals in video games: Implications for gender socialization and aggressive behavior. Sex Roles, 38(5/6), 425-442.

Dyer-Whiteford, N., \& de Peuter, G. (2009). Games of empire: Global capitalism and video games. Minneapolis: University of Minnesota Press.

Hebdige, D. (1979). Subculture: The meaning of style. London: Routledge.

Jameson, F. (1983). The political unconscious. London: Routledge.

Jenkins, H. (2004). Games design as narrative architecture. In N. Wardrip-Fruin \& P. Harrigan (Eds.), First person: New media as story, performance, and game. Cambridge: MIT Press.

Kafai, Y. B., Richard, G. T., \& Tynes, B. M. (2016). Diversifying Barbie and Mortal Kombat: Intersectional perspectives and inclusive designs in gaming. Pittsburgh: ETC Press.

Kassabian, A. (2001). Hearing film: Tracking identifications in contemporary hollywood film music. London: Routledge.

Kelly, A. (2016). Rediscovering the quirky futurism of Beneath a Steel Sky. PCGamer. (review). Available at https://www.pcgamer.com/rediscovering-the-quirky-futurism-of-beneath-a-steel-sky/.

Leonard, D. (2006). Not a hater, just Keepin' it real: The importance of race- and gender-based game studies. Games and Culture, 1(1), 83-88.

Lynch, T., Tompkins, J. E., van Driel, I. I., \& Fritz, N. (2016). Sexy, strong, and secondary: A content analysis of female characters in video games across 31 years. Journal of Communication, 66(4), 564-584.

Mad Max 2. (1981). Dir. George Miller (Film). Australia: Kennedy Miller Productions.

Miller, K. (2007). Jacking the dial: Radio, race and place in "grand theft auto". Ethnomusicology, 51(3), $402-438$.

Monson, M. (2012). Race-based fantasy realm: Essentialism in the world of warcraft. Games and Culture, 7(1), 48-71.

Moore, A., \& Gibbons, D. (1986-1987). Watchmen (comic book series). USA: DC Comics.

Orwell, G. (1949). Nineteen eighty-four. London: Secker \& Warburg.

Rettberg, S. (2008). Corporate ideology in world of warcraft. In H. G. Corneliussen \& J. W. Rettberg (Eds.), Digital culture, play, and identity: A world of warcraft reader (pp. 19-38). Cambridge, MA: MIT Press.

Ruberg, B., \& Shaw, A. (2017). Queer game studies. Minneapolis: University of Minnesota Press.

Sargent, L. T. (1994). The three faces of utopianism revisited. Utopian Studies, 5(1), 1-37.

Star Trek: The Next Generation. (1987-1994). US: First-run syndication.

White, L. (2009). Foster's lager: From local beer to global icon. Marketing Intelligence and Planning, 27(20), 177-190.

\section{Media References:}

Assassin's Creed: Syndicate. (2015). Ubisoft Quebec. France: Ubisoft.

Beneath a Steel Sky. (1994). Revolution software. UK: Revolution Software.

Brazil. (1985). Dir. Terry Gilliam. USA: Embassy International Pictures and Brazil Production.

Dragon Age 2. (2011) BioWare. USA: Electronic Arts.

Final Fantasy VII. (1997) Squaresoft. Japan: Playstation. 